\title{
EMOTIONAL INTELLIGENCE AMONG HEALTH SCIENCES STUDENTS
}

\author{
Pramila Pudasaini \\ Research scholar ITM University Gwalior, MP, India. \\ Vandana Bharti \\ Associate Professor, ITM University Gwalior, MP, India.
}

Biju Kumar Thapalia,

Professor, Faculty of Management, Purbanchal University, Biratnagar, Nepal Nepal.

\begin{abstract}
Emotional intelligence (EI) implies capability to supervise self \& other people perception \& sentiments. Explaining further, four common constituents of Emotional intelligence are self-realization, self-administration, social consciousness and social affinity administration. The purpose of studying emotional intelligence is to identity emotional intelligence among health professional students and to figure out its association with selected demographic variables.
\end{abstract}

Key words: Emotional Intelligence, Health Sciences students, Yeti Health Science Academy

Cite this Article: Pramila Pudasaini, Vandana Bharti and Biju Kumar Thapalia, Emotional Intelligence Among Health Sciences Students, International Journal of Management, 11(12), 2020, pp. 2030-2033.

http://iaeme.com/Home/issue/IJM?Volume=11\&Issue=12

\section{INTRODUCTION}

Emotional intelligence (EI) implies capability to supervise self \& other people perception \& sentiments. Explaining further, four common constituents of Emotional intelligence are selfrealization, self-administration, social consciousness and social affinity administration (Raghubir, 2018). Pupils with advanced emotional intelligence were healthy and happy (Ghahramani, Jahromi, Khoshsoroor, Seifooripour \& Sepehrpoor, 2019).

Study showed a straight connection of medical education in intelligence capabilities, which shows that medical education is an ideal to increase social relationship (Johnson, 2015). Conveying one's perception and hearing to other's increase emotional intelligence and become helpful for students in initial years of medical training. It helps to increase extents of consciousness of emotional intelligence in a person (Abe et al., 2013). Practicing emotional 
intelligence increases the mental well-being and impacts on anxiety, relationships, tension, sadness \& belligerence (Aghajani Inche Kikanloo et al., 2019). Objectives: The purpose of studying emotional intelligence is to identity emotional intelligence among health professional students and to figure out its association with selected demographic variables.

\section{METHODOLOGY}

The cross-sectional descriptive study was acquired during process. The study site was Yeti Health Science Academy, Kathmandu. The sample of the study were students of BPH, PBNS and Bsc Nursing program. Non probability, purposive sampling technique was used in the work process. The specimen size was 100. A standard tool i.e. The Schutte Self Report Emotional Intelligence Test (SSEIT) was used to collect the data. It is a 33 Items Likert's Scale (Schutte NS, 1998).Self-managed poll method was used to gather information. Ethical clearance was done from IRC of Yeti Health Science Academy and consent was taken from the concerned authority and participants for data collection.

\subsection{Results}

Chart 1: Demographic data of testifiers $n=100$

\begin{tabular}{|l|l|l|}
\hline \multicolumn{1}{|c|}{ Variables } & Frequency & Percentage \\
\hline Program & & \\
\hline BPH & 36 & 36 \\
\hline PBNS & 41 & 41 \\
\hline Bsc Nursing & 23 & 23 \\
\hline Age & & \\
\hline$<20 y r s$ & 37 & 37 \\
\hline $20-30 y r s$ & 60 & 60 \\
\hline$>30 y r s$ & 3 & 3 \\
\hline Gender & & \\
\hline Male & 28 & 28 \\
\hline Female & 72 & 72 \\
\hline
\end{tabular}

Chart 1 depicts that forty one percentage of the respondents were PBNS students followed by thirty six percentage of BPH students and twenty three percentage of BSc Nursing students. Majority $(60 \%)$ of the testifiers were of age group 20-30 years followed by thirty seven percentage of the testifiers of age group less than 20 years. Majority $(72 \%)$ of the testifiers were female.

Chart 2. Extent of Emotional Intelligence of the Testifiers. $n=100$

\begin{tabular}{|l|l|l|l|l|}
\hline Program & $\begin{array}{l}\text { Below Average EI } \\
(<\mathbf{5 5})\end{array}$ & $\begin{array}{l}\text { Average EI } \\
\mathbf{( 5 5 - 8 5 )}\end{array}$ & $\begin{array}{l}\text { Above average EI } \\
(\mathbf{8 5 5})\end{array}$ & Mean Score \\
\hline BPH & 0 & 0 & 36 & 114.53 \\
\hline PBNS & 0 & 0 & 41 & 125.46 \\
\hline BSc Nursing & 0 & 2 & 21 & 116.74 \\
\hline Total & 0 & 2 & 98 & 119 \\
\hline
\end{tabular}

Chart 2 depicts that majority (98\%) of testifiers have above average extent of emotional intelligence and only two percent of the testifiers have average emotional intelligence. Cent percent of testifiers of BPH program and PBNS program have above average EI. The mean 
score of EI among BPH, PBNS and BSc Nursing students are 114.53, 125.46, and 116.74 respectively. The total mean score of EI is 119.

Chart 3. Association of Emotional Intelligence with selected demographic variables. $\quad n=100$

\begin{tabular}{|l|l|l|l|l|}
\hline \multicolumn{1}{|c|}{ Variable } & $\begin{array}{c}\text { EI Less than or } \\
\text { equal to mean } \\
(\leq \mathbf{1 1 9})\end{array}$ & $\begin{array}{c}\text { Greater than } \\
\text { mean }(\mathbf{1 1 9 )}\end{array}$ & P- Value & Remarks \\
\hline Program & & & & \\
\hline BPH & 22 & 14 & 0.01 & Significant \\
\hline PBNS & 11 & 30 & & \\
\hline BSc Nursing & 10 & 13 & & Non-Significant \\
\hline Age & & & & \\
\hline$<20 y r s$ & 18 & 19 & 0.24 & \\
\hline $20-30 y r s$ & 25 & 35 & & Significant \\
\hline$>30 y r s$ & 0 & 3 & & \\
\hline Gender & & 11 & 0.03 & \\
\hline Male & 17 & 46 & & \\
\hline Female & 26 & & & \\
\hline
\end{tabular}

\subsection{Statistical Test: Chi-square test}

Chart 3 depicts a significant link between the Emotional Intelligence \& different program of health sciences. The P-value is $0.01(<0.05)$ at $95 \%$ confidence interval. No remarkable link was found between EI \& age $(\mathrm{p}=0.24)$. There was a significant association between EI and gender $\mathrm{P}=0.03((<0.05)$.

\section{DISCUSSION}

Present study shows that the majority (98\%) of the health sciences students had good emotional intelligence. Similar study was done in Nepal in Sanjeevani college of Medical Sciences. Work shows that approximately $46 \%$ of pupils had usual \& approximately $15 \%$ had elevated extent of emotional intelligence. Eating habits, Guardian's educational qualification, age of pupils, environment at work place \& worship beliefs were the elements that influenced emotional intelligence of UG nursing pupils. The work process shows that approximately $(52 \%)$ of the nursing pupils had usual extent of emotional intelligence. (Sinha B et al, 2018). There was slight difference in the finding of the study; it may be because of the differences in the sample.

Another study compared nursing pupil's emotional intelligence dexterity between King Saud University (Riyadh) and Tanta University (Egypt). It found numerically notable constructive connection between absolute emotional intelligence \& scores mother's education $\&$ household earnings ( $p=0.004$ and $p=0.034$ respectively) of Tanta pupils but present work reveals remarkable link between emotional intelligence \& selected demographic variables like program and gender (Moawed S, Gemeay ME, \& Elsayes HA, 2017).

Similar findings were present in the study conducted in Chennai among medical pupils. Male \& female pupils, both had high extent of emotional intelligence (Sundararajan S, GopichandranV, 2018) and also consistent with the findings of study conducted amid PG medical pupils at Delhi in which average scores of Emotional intelligence amid participators was 124.4 with computation of 12.8 (Ravikumar R, Rajoura OP, Sharma R, 2017). 


\section{CONCLUSION}

The Emotional Intelligence among health sciences students was found to be very good and study shows a considerable link between emotional intelligence \& program, gender. This might lead to better academic achievement and outcome.

\section{REFERENCES}

[1] Abe, K., Evans, P., Austin, E. J., Suzuki, Y., Fujisaki, K., Niwa, M., \& Aomatsu, M. (2013). Expressing one's feelings and listening to others increases emotional intelligence: A pilot study of Asian medical students. BMC Medical Education, 13(1), 1.

[2] Aghajani Inche Kikanloo, A., Jalali, K., Asadi, Z., Shokrpour, N., Amiri, M., \& Bazrafkan, L. (2019). Emotional Intelligence Skills: Is Nurses' Stress and Professional Competence Related to their Emotional Intelligence Training? A quasi experimental study. Journal of Advances in Medical Education \& Professionalism, 7(3), 138-143.

[3] Binisha S, Kushwaha M (2017). Emotional Intelligence among Undergraduate Nursing Students. International Journal of scientific and research publications, 7(12).

[4] Ghahramani, S., Jahromi, A. T., Khoshsoroor, D., Seifooripour, R., \& Sepehrpoor, M. (2019). The relationship between emotional intelligence and happiness in medical students. Korean Journal of Medical Education, 31(1), 29-38.

[5] Johnson, D. R. (2015). Emotional intelligence as a crucial component to medical education. International Journal of Medical Education, 6, 179-183.

[6] Raghubir, A. E. (2018). Emotional intelligence in professional nursing practice: A concept review using Rodgers's evolutionary analysis approach. International Journal of Nursing Sciences, 5(2), 126-130.

[7] Ravikumar R, Rajoura O P, Sharma R, et al. (January 22, 2017) A Study of Emotional Intelligence among Postgraduate Medical Students in Delhi. Cureus 9(1): e989. doi: $10.7759 /$ cureus.989

[8] Schutte NS, Malouff JM, Hall LE, Haggerty DJ, Cooper JT, Golden CJ, et al (1998). Development and validation of a measure of emotional intelligence. Personality and Individual Differences, 25(2):167-77.

[9] Sundararajan S, GopichandranV (2018). Emotional intelligence among medical students: a mixed methods study from Chennai, India. BMC Med Educ,18(97). https://doi: 10.1186/s12909-018-1213-3

[10] Maowed S, Gemeay Em, ELsayes HA (2017). Emotional Intelligence among nursing students: A comparative study. International Journal of Novel Research in Health care and Nursing, 4(1).

[11] John J Binder (2006): 